\title{
Erratum to: Bench-Top Type In Vivo EPR Spectrometer for Estimating the Renal Reducing Ability of a Rat
}

\author{
Hidekatsu Yokoyama • Toshiyuki Sato • \\ Takaaki Oteki
}

Published online: 16 November 2012

(C) Springer-Verlag Wien 2012

\section{Erratum to: Appl Magn Reson (2012) 43:421-430 DOI 10.1007/s00723-012-0343-8}

Owing to a most unfortunate oversight, the wrong author was given as being deceased. The footnote should read: "Hidekatsu Yokoyama: Deceased".

The online version of the original article can be found under doi:10.1007/s00723-012-0343-8.

H. Yokoyama $(\bowtie)$

Department of Pharmaceutical Sciences, International University of Health and Welfare, 2600-1 Kitakanemaru, Otawara 324-8501, Japan

e-mail: yokohide@iuhw.ac.jp

H. Yokoyama

Yamagata Promotional Organization for Industrial Technology, 2-2-1 Matsuei,

Yamagata 990-2473, Japan

T. Sato

Yamagata Research Institute of Technology, 2-2-1 Matsuei, Yamagata 990-2473, Japan

T. Oteki (凶)

Center for Clinical Medicine and Research, International University of Health and Welfare, 537-3 Iguchi, Nasushiobara 329-2763, Japan

e-mail: oteki@iuhw.ac.jp 